\title{
Oral health condition and development of frailty over a 12-month period in community- dwelling older adults
}

\author{
Laura Bárbara Velázquez-Olmedo ${ }^{1}$, Socorro Aída Borges-Yáñez ${ }^{2}$, Patricia Andrade Palos ${ }^{3}$, Carmen García-Peña ${ }^{4}$, \\ Luis Miguel Gutiérrez-Robledo ${ }^{4}$ and Sergio Sánchez-García ${ }^{{ }^{*}}$
}

\begin{abstract}
Background: To determine the association between oral health condition and development of frailty over a 12-month period in community-dwelling older adults.

Methods: Population-based, case-cohort study derived from the Cohort of Obesity, Sarcopenia, and Frailty of Older Mexican Adults (COSFOMA) study, including data from years 2015 and 2016. Using latent class analysis, we determined the oral health condition of older adults with teeth $\left(\mathrm{t}_{0}\right)$, i.e., functional teeth, presence of coronal caries, root caries, periodontal disease, dental calculus, dental biofilm, root remains, xerostomia, and need for dental prosthesis. Edentulous was considered as a separate class. Criteria of the Frailty Phenotype $\left(\mathrm{t}_{1}\right)$ by Fried et al. were used: weight loss, self-report of exhaustion, walking speed, decreased muscle strength, and low physical activity. The presence of three or more criteria indicated a frail condition. The strength of the association (odds ratio, OR) between oral health condition and development of frailty was estimated through bivariate analysis. Multiple logistic regression was used to adjust for the other variables of study: sociodemographic data (sex, age, marital status, level of education, paid work activity, and living alone), comorbidities, cognitive impairment, depressive symptoms, nutritional status, and use of oral health services.
\end{abstract}

Results: 663 non-frail older adults were evaluated, with a mean age of 68.1 years (SD \pm 6.1 ), of whom 55.7\% were women. In $t_{0}$, a three-class model with an acceptable value was obtained (entropy $\left.=0.796\right)$. The study participants were classified as: edentulous persons (6.9\%); Class $1=$ Acceptable oral health (57.9\%); Class 2 = Somewhat acceptable oral health (13.9\%); and Class $3=$ Poor oral health (21.3\%). In $t_{1}, 18.0 \%(n=97)$ of participants developed frailty. Using Acceptable oral health (Class 1) as a reference, we observed that older adults with edentulism (OR 4.1, OR adjusted 2.3) and Poor oral health (OR 2.4, OR adjusted 2.2) were at an increased risk of developing frailty compared to those with Acceptable oral health.

Conclusion: Older adults with edentulism and poor oral health had an increased risk of developing frailty over a 12-month period.

Keywords: Oral health, Frailty, Older adults

\footnotetext{
*Correspondence: sergio.sanchezga@imss.gob.mx

${ }^{5}$ Unidad de Investigación Epidemiológica y en Servicios de Salud, Área Envejecimiento, Centro Médico Nacional Siglo XXI, Instituto Mexicano del Seguro Social, Avenida Cuauhtémoc No. 330, Edificio CORCE, Tercer Piso. Col. Doctores. Alcaldía Cuauhtémoc, 06720 Ciudad de México, México

Full list of author information is available at the end of the article
}

\section{Background}

In recent decades, the population of older adults has increased globally [1] and projections indicate that it will continue to rise; between 2000 and 2050, the proportion of older adults will increase from 11.0 to $22.0 \%$. 
It is estimated that for the year 2050, the number of dependent older adults will be multiplied by four in developing countries due to physical and mental health problems, as well as frailty $[2,3]$.

Frailty is one of the most common conditions faced by older adults. It is a physiological state characterized by decreased body capacity and resistance to stressors, resulting from the cumulative decline of multiple physiological systems $[4,5]$.

Several potential risk factors could be responsible for the development of frailty, such as: Chronic diseases (diabetes, cardiovascular disease, stroke, arthritis, chronic obstructive pulmonary disease, cognitive impairment); physiological factors (active inflammatory processes, anemia, age, immune system dysfunction, endocrine system disruption, underweight or overweight and malnutrition) [6, 7]; sociodemographic and psychological factors (gender, low socioeconomic status, depression, race or ethnicity); and disabilities affecting activities of daily living [6].

Frailty is associated with an increased state of vulnerability and dependence, which increases the risk of adverse outcomes such as falls, delirium and disability [3-5].

Older adults also suffer from poor oral health due to conditions like tooth decay, periodontal disease, and edentulism, among others. These issues accumulate throughout the life course and are exacerbated by infrequent visits to oral health professionals, compared with the general population [8-10].

Oral health deficits can have a biological impact, leading to health problems such as change in salivary flow, altered sense of taste, change in food consumption and inadequate diet, weight loss, low physical function, and presence of chronic inflammation that is caused by poor periodontal status, which in turn is a risk factor for frailty [11-13].

Poor oral health is associated with frailty in older adults [11-14]. The relationship between oral deficits (need for dental prosthesis, number of teeth, periodontal disease, edentulism, oral pain, and chewing capacity) and frailty has been studied in cross-sectional and longitudinal studies [13-17]; however, most studies have considered each of the deficits individually. Two longitudinal studies have investigated this relationship from a holistic approach, considering several oral deficits in order to gain a better understanding of how they interact with frailty $[18,19]$.

Oral health is not measured directly, but rather is inferred from a set of observed explanatory variables (oral health deficits). Therefore, latent class analysis was used to determine oral health conditions (latent classes) in the sample of older adults. $[9,10]$. This study aimed to determine the strength of the association between oral health conditions and development of frailty over a 12-month period in older adults.

\section{Methods}

We conducted a population-based, case-cohort [20] study derived from the Cohort of Obesity, Sarcopenia, and Frailty of Older Mexican Adults (COSFOMA). COSFOMA is a longitudinal study that began in 2014 using a random population sample of 1252 older individuals (60 years and older) who were affiliated with the Mexican Social Security Institute (IMSS). The sampling procedure and the description of the study have been previously documented [21]. The IMSS is part of Mexico's social health protection system; it provides medical services to employees and their families, as well as financial pension benefits for disability, advanced age or retirement. IMSS covers $36.5 \%$ of Mexico City's population and approximately $50.9 \%$ of older adults [22].

For this study, information from the second (2015) and third wave of data collection (2016) was considered for a 12-month follow-up. We selected the second wave because questions regarding oral health deficits were included that year. The study adhered to national and international ethical guidelines and regulations in research involving human beings, and informed consent was obtained from all participants prior to data collection. This research protocol was approved by IMSS's National Committee for Scientific Research (Health Research Committee, Ethics Committee on Health Research, and Biosafety Committee on Health Research), registration number: R-2017-785-11.

Using data from the second collection period in 2015 $\left(t_{0}\right)$, older adults who met two of the five criteria to determine frailty phenotype, according to Fried et al. (Table 1), were selected for the study $[5,21]$.

A total of 663 non-frail older adults were identified. Those with missing information and who did not attend follow-up or died were excluded. The final sample comprised 539 older adults in the 12-month follow-up period (Fig. 1). Invitation letters were sent to the homes of the selected individuals, specifying the date and time that they should attend the XXI Century National Medical Center in Mexico City. A phone number was provided for those who needed to change their appointments. Subsequently, they received a telephone call to remind them about their appointment and new schedules were organized for those who could not attend as planned.

Data on oral deficits were obtained through a clinical dental evaluation by two oral health professionals after previous standardization of procedures (Kappa $\geq 0.80$ ). Disposable gloves, front lamp, mirror number 5 (front reflection), and CPI probe (WHO style-probe (CP11.5B)) were used. The examination included presence of: 
Table 1 Criteria for frailty phenotype [21]

Weight los

Self-report of exhaustion

Low physical activity

Slowness

Weakness (low grip strength)
Differences between weight during the previous year and actual weight were calculated. Subjects with weight loss $>10 \mathrm{lb}(4.5 \mathrm{~kg})$ during this period were classified as positive for the criterion of weight loss

Two questions were used from the revised version of 35 items of the Center for Epidemiologic Studies Depression Scale (CESD-R) adapted for older Mexican adults to determine the criteria of exhaustion. Items considered were:"I felt that everything I did was with difficulty" and "I could not continue." Considered positive for the criteria was if the participant responded: "During 5-7 days in the past week" or "Almost every day for 2 weeks"

Level of physical activity during the previous week was evaluated with the Physical Activity Scale for the Elderly (PASE) questionnaire that included self-reported occupational, domestic, and recreational activities. Low physical activity was considered as $\leq 58.6$ points for men and $\leq 56.4$ points for women (low point quartile of PASE)

Walking time was estimated for $4.5 \mathrm{~m}$ (15 ft), stratified by sex and stature. Walking distance was considered in women with a height $\leq 159 \mathrm{~cm}$, time $\geq 7 \mathrm{~s}$ and height $>159 \mathrm{~cm}$, time $\geq 6 \mathrm{~s}$. Walking distance was considered in men with a height $\leq 173 \mathrm{~cm}$, time $\geq 7 \mathrm{~s}$ and with a height $<173 \mathrm{~cm}$, time $\geq 6 \mathrm{~s}$

Grip strength of the nondominant hand was evaluated using dynamometry (Takei T.K.K5001, Takei Scientific Instruments Co. Ltd., Tokyo, Japan) with values stratified by sex and BMl quartiles. In women, low grip strength was considered with $\mathrm{BMI} \leq 23.0, \leq 17 \mathrm{~kg} ; \mathrm{BMI} 23.1-26.0, \leq 17.3 \mathrm{~kg} ; \mathrm{BMI} 26.1-29.0, \leq 18.0 \mathrm{~kg} ; \mathrm{BMI}>29, \leq 21.0 \mathrm{~kg}$. In men, it was considered with $\mathrm{BMI} \leq 24.0, \leq 29 \mathrm{~kg} ; \mathrm{BMl} 24.1-26.0, \leq 30.0 \mathrm{~kg} ; \mathrm{BMI} 26.1-28.0, \leq 30 \mathrm{~kg} ; \mathrm{BMI}>28, \leq 32.0 \mathrm{~kg}$

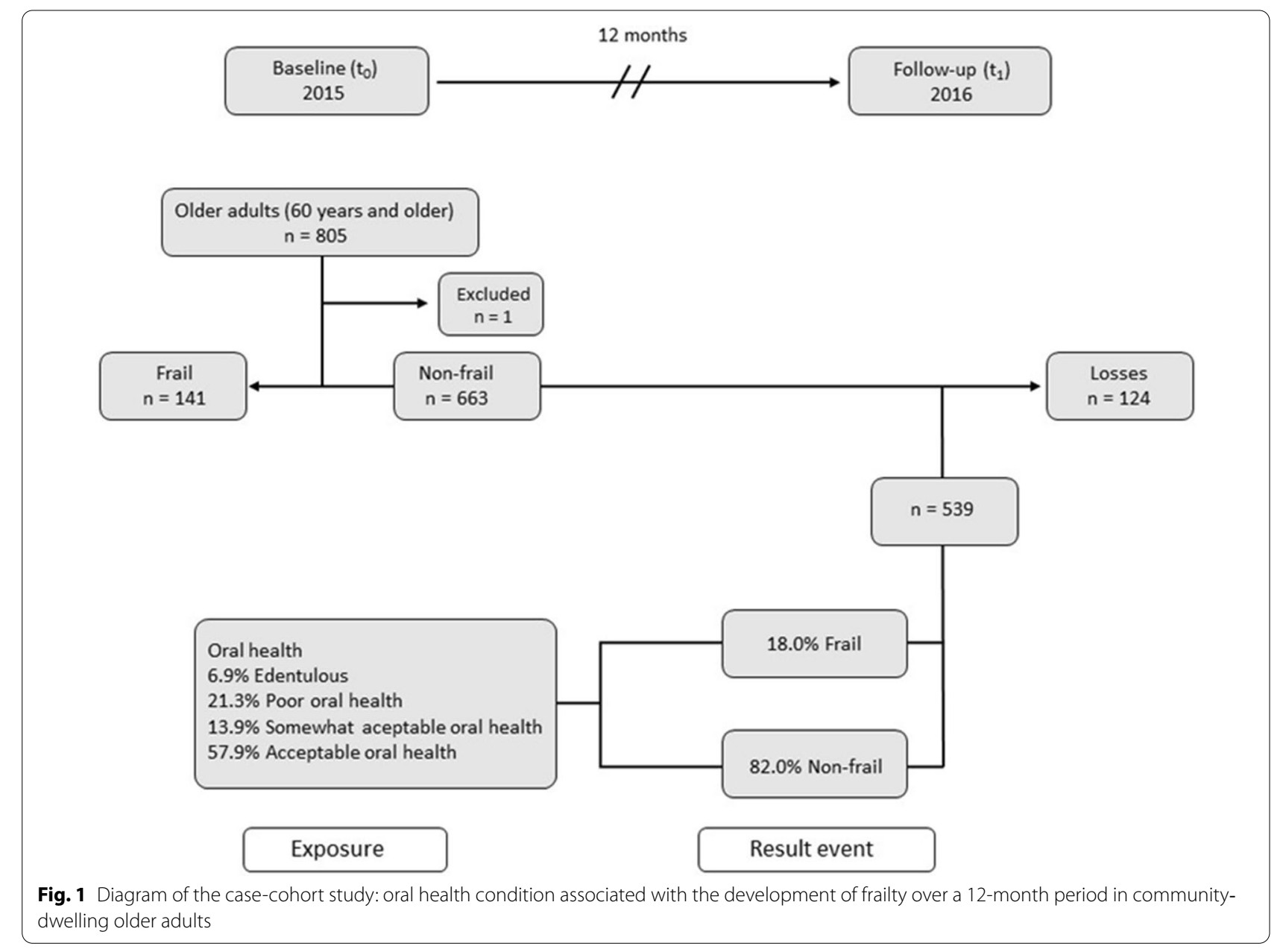

Functional teeth ( $<20$ teeth, $\geq 20$ teeth); coronal caries; root caries (presence/absence); periodontal disease (presence/absence of clinical attachment, $\geq 4 \mathrm{~mm}$ in at least one tooth); dental calculus (presence/absence); dental biofilm (presence/absence); root remains (presence/ absence) [23]; xerostomia, for which the Xerostomia Inventory ( $\geq 28$ points) was used [24]; need for removable dental prosthesis (absence of stability and retention) 
[25]; and the presence or absence of edentulism (total absence of teeth in the oral cavity). These oral conditions were used to perform latent class analysis, categorizing oral health in older adults; edentulism was not included because it is an independent category.

Other variables used in the study were sociodemographic characteristics (sex, age, marital status, level of education, paid work activity, and living alone). For comorbidities (the information was self-reported), data from the Elixhauser Index was taken as a reference [26]. Cognitive function was evaluated using the Mini-Mental State Examination (MMSE); a score $\leq 23$ was considered as cognitive impairment, adjusted for education level [27]. Depression was assessed through the Center for Epidemiologic Studies Depression Scale-Revised (CESD-R); a score of $\geq 57$ points indicates presence of depressive symptoms [28]. Finally, nutritional status was evaluated using the Mini Nutritional Assessment (MNA), in which $<17$ points indicate malnutrition; the categories "risk of malnutrition and satisfactory nutrition" were combined into a single variable [29]. Use of dental services (self-reported) in the past 12-months was recorded (Yes/No).

To determine the frailty phenotype after 12-months $\left(t_{1}\right)$, the database from the third data collection period, spanning April to September 2016, was used. The following criteria were considered: weight loss, self-report of exhaustion, low level of physical activity, slow walking speed, and low muscle strength (Table 1). For this study, frailty in older adults was defined as meeting three or more of the above criteria for both baseline and followup $[5,18]$.

\section{Statistical analysis}

Descriptive statistics were used to obtain the frequency, mean (Standard Deviation, SD), and median (percentile 25-75) of the variables that were considered at the start of tracking $\left(\mathrm{t}_{0}\right)$. For high coronal caries, greater than or equal to 2 decayed teeth (75th percentile value) was considered as a cutoff point.

To categorize oral health in older adults at the onset of a 12-month follow-up, a Latent Class Analysis (LCA) was performed. The presence of $<20$ functional teeth, coronal caries $(\geq 2)$, root caries, periodontal disease, dental calculus, dental biofilm, root remains, xerostomia, and need of dental prosthesis was considered for this analysis. Latent Class Analysis (LCA) is a person-centered approach that aims to classify individuals into mutually exclusive groups by building oral health categories that are based on oral health deficits $[9,10]$.

In this study, LCA was used to create an optimal number of classes to categorize oral health in older adults [10]. The choice of the model, in terms of the number of oral health classes, was determined by progressively increasing the number and contrasting the results with those of each subsequent model using the Lo-Mendell-Rubin (LMR) likelihood ratio test of model fit; in the LMR, the presence of a non-significant probability $(p>0.05)$ suggests that the previous model (with fewer classes) is preferable [30,31].

A combination of the Akaike Information Criterion (AIC) and the Bayesian Information Criterion (BIC) [32, 33] was used to evaluate the goodness of fit of the model, as well as the entropy values [30]. Although there is no standard threshold for evaluating entropy, values close to 1.0 are the most desirable $[9,10,32]$. Finally, the models were interpreted in terms of their theoretical and practical consistency. The most simple and parsimonious model was selected, using the software Mplus, version 7.0.

The strength of the association (odds ratio, OR and 95\% confidence interval, 95\% CI) between oral health in older adults and the development of frailty over a period of 12-months was estimated. Bivariate and multiple logistic regression was used to adjust for the other variables of study: sociodemographic data (sex, age, marital status, level of education, paid work activity, and living alone), comorbidities, cognitive impairment, depressive symptoms, nutritional status, and use of oral health services. The group of non-frail older adults was taken as a reference. The IBM-SPSS statistical package for Windows, Version 23.0 (IBM Corp. Released 2015, Armonk, NY: IBM Corp.) was used to perform the analyses.

\section{Results}

The baseline assessment $\left(\mathrm{t}_{0}\right)$ was carried out in 2015 . A total of 805 older adults were included in the study, with a mean (SD) age of 69.0 (6.7) years. Of these, 58.5\% $(\mathrm{n}=471)$ were women and $41.5 \%(\mathrm{n}=334)$ men, with a mean age of $69.2(6.5)$ and 68.9 (6.8) years, respectively. Frailty was found in $17.5 \%(\mathrm{n}=141)$ and non-frailty in 82.5\% $(\mathrm{n}=664)$ of participants. After exclusion of 141 frail persons in $\mathrm{T}_{0}$ and one person who rejected oral examination, the final population was 663 older adults. The mean age was $68.1(6.1) ; 55.7 \%(n=369)$ were women and $44.3 \%(n=294)$ men, with a mean age of 67.7 (6.0) and 68.7 (6.2), respectively.

For the 12-month follow-up, $81.3 \%(n=539)$ of participants were available. The mean age was $67.9(6.0)$; $55.1 \%(\mathrm{n}=297)$ were women and $44.9 \%(\mathrm{n}=242)$ men, with a mean age of $67.4(5.8)$ and 68.6 (6.1), respectively. Furthermore, $18.7 \%(n=124)$ of participants were lost to follow-up, where: $5.7 \%(\mathrm{n}=7)$ died, $4.8 \%(\mathrm{n}=6)$ were sick at home; $31.5 \%(n=39)$ refused to participate; $48.3 \%$ $(n=60)$ could not be located; $5.7 \%(n=7)$ did not have someone to accompany them to the study; $2.4 \%(n=3)$ 
had some disability; and $1.6 \%(n=2)$ worked, so they were not able to attend their appointment (Fig. 1).

Table 2 shows baseline characteristics according to frailty condition in follow-up; $18.0 \%(n=97)$ of older adults developed frailty over a period of 12-months (2015-2016). A heterogeneous distribution according to frailty and age was observed. In addition, $62.0 \%(n=362)$ reported being married or in a free union, $40.1 \%(\mathrm{n}=216)$ performed some paid work activity, and $3.5 \%(n=19)$ had depressive symptoms, while $63.6 \%(n=343)$ reported not having used oral health services in the past 12-months, with heterogeneity observed for frailty. Non-significant differences were noted in the remaining characteristics.

At the start of the study (baseline $\left.t_{0}\right), 6.9 \%(n=37)$ of participants were edentulous and $93.1 \%(n=502)$ had teeth (1-28 teeth). The deficits presented in edentulous persons were xerostomia in $16.2 \%$ and need for dental prosthesis (absence of stability and retention) in $70.3 \%$. Of the dentate ( $<20$ functional teeth) older adults (52.8\%), 28.5\% had coronal caries ( $\geq 2$ teeth), $19.0 \%$ root caries, $88.2 \%$ periodontal disease, $22.1 \%$ dental calculus, $26.1 \%$, dental biofilm, $15.3 \%$, in root remains, $13.5 \%$, xerostomia, and $29.7 \%$ needed a dental prosthesis. Following the criteria for latent class formation, the decision was made to form three classes to categorize oral health from an entropy of .796, an Akaike Information Criterion (AIC) of 4254.034, a Bayesian Information Criterion (BIC) of 4376.373, and a Lo-Mendell-Rubin adjusted likelihood ratio test of $p=.0394$ (Table 3).

Figure 2 shows the probability of different oral health deficits in dentate older adults in each of the three oral health classes. Regarding the conditional probabilities of oral health deficits within each class, for Class 2, we observed a noticeable increase in the probability of $<20$ functional teeth, periodontal disease, root remains, and the need for dental prosthesis compared with Class 1 . Class 3 showed an increase in the probability of coronal caries, root caries, periodontal disease, dental calculus, dental biofilm, and root remains compared with Class 2. According to these probabilities, the categories were named as follows: Acceptable oral health (Class 1); Somewhat acceptable oral health (Class 2); and Poor oral health (Class 3). Finally, the following four categories were obtained: Edentulous older adults $6.9 \%(n=37)$; Acceptable oral health (Class 1) 57.9\% ( $\mathrm{n}=312)$; Somewhat acceptable oral health (Class 2$) 13.9 \%(n=75)$; and Poor oral health (Class 3) 21.3.\% $(n=115)$.

Using the oral health categories at baseline $\left(t_{0}\right)$, the strength of the association was estimated from the bivariate logistic regression analysis for the development of frailty at 12-months of follow-up $\left(t_{1}\right)$. The results showed that edentulous older adults and those with poor oral health were 4.1 times (95\% CI 1.9-8.4) and 2.4 times
Table 2 Basal characteristics of the study sample of older adults

\begin{tabular}{|c|c|c|c|c|}
\hline & $\begin{array}{l}\text { Total } \\
\%(n)\end{array}$ & $\begin{array}{l}\text { Non-frail } \\
\%(n)\end{array}$ & $\begin{array}{l}\text { Frail } \\
\%(n)\end{array}$ & $p$-value* \\
\hline & $100(539)$ & $82.0(442)$ & $18.0(97)$ & \\
\hline \multicolumn{5}{|l|}{ Sex } \\
\hline Men & $44.9(242)$ & $46.2(204)$ & $39.2(38)$ & .211 \\
\hline Women & $55.1(297)$ & $53.8(238)$ & $60.8(59)$ & \\
\hline \multicolumn{5}{|l|}{ Age (years) } \\
\hline$\geq 80$ & $5.8(31)$ & $4.1(18)$ & $13.4(13)$ & $<.001$ \\
\hline $70-79$ & $27.0(146)$ & $25.3(112)$ & $35.1(34)$ & \\
\hline $60-69$ & $67.2(362)$ & $70.6(312)$ & $51.5(50)$ & \\
\hline \multicolumn{5}{|l|}{ Marital status } \\
\hline Widowed & $18.2(98)$ & $18.3(81)$ & $17.5(17)$ & .743 \\
\hline Single & $19.8(107)$ & $19.2(85)$ & $22.7(22)$ & \\
\hline Married/free union & $62.0(334)$ & $62.4(276)$ & $59.8(58)$ & \\
\hline \multicolumn{5}{|l|}{ Education level } \\
\hline None & $3.0(16)$ & $3.2(14)$ & $2.1(2)$ & .093 \\
\hline $1-6$ years & $25.4(137)$ & $23.5(104)$ & $34.0(33)$ & \\
\hline$\geq 7$ years & $71.6(386)$ & $73.3(324)$ & $63.9(62)$ & \\
\hline \multicolumn{5}{|l|}{ Salaried work } \\
\hline No & $59.9(323)$ & $59.3(262)$ & $62.9(61)$ & .511 \\
\hline Yes & $40.1(216)$ & $40.7(180)$ & $37.1(36)$ & \\
\hline \multicolumn{5}{|l|}{ Living alone } \\
\hline Yes & $12.1(65)$ & $12.0(53)$ & $12.4(12)$ & .917 \\
\hline No & $87.9(474)$ & $88.0(389)$ & $87.6(85)$ & \\
\hline \multicolumn{5}{|l|}{ Comorbidities } \\
\hline$\geq 2$ & $18.6(100)$ & $18.3(81)$ & $19.6(19)$ & .541 \\
\hline 1 & $27.1(146)$ & $26.3(116)$ & $30.9(30)$ & \\
\hline 0 & $54.3(293)$ & $55.4(245)$ & $49.5(48)$ & \\
\hline \multicolumn{5}{|l|}{ Cognitive impairment } \\
\hline Yes & $17.4(94)$ & $16.1(71)$ & $23.7(23)$ & .072 \\
\hline No & $82.6(445)$ & 83.9 (371) & $76.3(74)$ & \\
\hline \multicolumn{5}{|l|}{ Depression } \\
\hline Yes & $3.5(19)$ & $2.0(9)$ & $10.3(10)$ & $<.001$ \\
\hline No & $96.5(520)$ & 98.0 (433) & 89.7 (87) & \\
\hline \multicolumn{5}{|l|}{ Malnutrition } \\
\hline Yes & $2.8(15)$ & $2.7(12)$ & $3.1(3)$ & .838 \\
\hline No & $97.2(524)$ & $97.3(430)$ & $96.9(94)$ & \\
\hline \multicolumn{5}{|l|}{$\begin{array}{l}\text { Use of oral health care } \\
\text { services in the past } \\
\text { 12-months }\end{array}$} \\
\hline Yes & 36.4 (196) & $66.3(293)$ & $51.5(50)$ & .006 \\
\hline No & $63.6(343)$ & 33.7 (149) & $48.5(47)$ & \\
\hline
\end{tabular}

*Chi-squared test

(95\% CI 1.4-4.1), respectively, more likely to become frail than older adults with acceptable oral health (Class I). The fully adjusted model showed that edentulous older adults $(\mathrm{OR}=2.4 ; 95 \%$ CI $1.0-5.1)$ and older adults with poor oral health $(\mathrm{OR}=2.2$; $95 \% \mathrm{CI} 1.2-3.8)$ were more likely to become frail than older adults with acceptable 
Table 3 Goodness of fit of the latent class model and conditional probability associated with oral health

\begin{tabular}{|c|c|c|c|c|}
\hline Number of latent classes & AIC & BIC & Entropy & $\begin{array}{l}\text { LMR test } \\
p \text {-value }\end{array}$ \\
\hline 1 & 4711.440 & 4749.407 & - & - \\
\hline 2 & 4288.799 & 4368.952 & .805 & .0000 \\
\hline 3 & 4254.034 & 4376.373 & .796 & .0394 \\
\hline 4 & 4239.008 & 4403.533 & .715 & .0954 \\
\hline Oral health deficits & $\begin{array}{l}\text { Edentulous } \\
6.9 \%(n=37)\end{array}$ & $\begin{array}{l}\text { Class } 3 \\
\text { Poor oral health } \\
21.3 \%(n=115)\end{array}$ & $\begin{array}{l}\text { Class } 2 \\
\text { Somewhat acceptable oral } \\
\text { health } \\
13.9 \%(n=75)\end{array}$ & $\begin{array}{l}\text { Class } 1 \\
\text { Acceptable } \\
\text { oral health } \\
57.9 \% \\
(\mathrm{n}=\mathbf{3 1 2})\end{array}$ \\
\hline$<20$ functional teeth & $100.0(37)$ & .939 & 1.000 & .256 \\
\hline Coronal caries & & .647 & .204 & .170 \\
\hline Root caries & & .531 & .160 & .072 \\
\hline Periodontal disease & & .970 & .911 & .843 \\
\hline Dental calculus & & .674 & .112 & .079 \\
\hline Dental biofilm & & .623 & .198 & .141 \\
\hline Root remains & & .343 & .319 & .041 \\
\hline Xerostomia & $16.2(6)$ & .164 & .239 & .099 \\
\hline Need of dental prosthesis & $70.3(26)$ & .594 & .948 & .022 \\
\hline
\end{tabular}

AIC Akaike Information Criterion, BIC Bayesian Information Criterion, LMR Lo-Mendell-Rubin likelihood ratio test

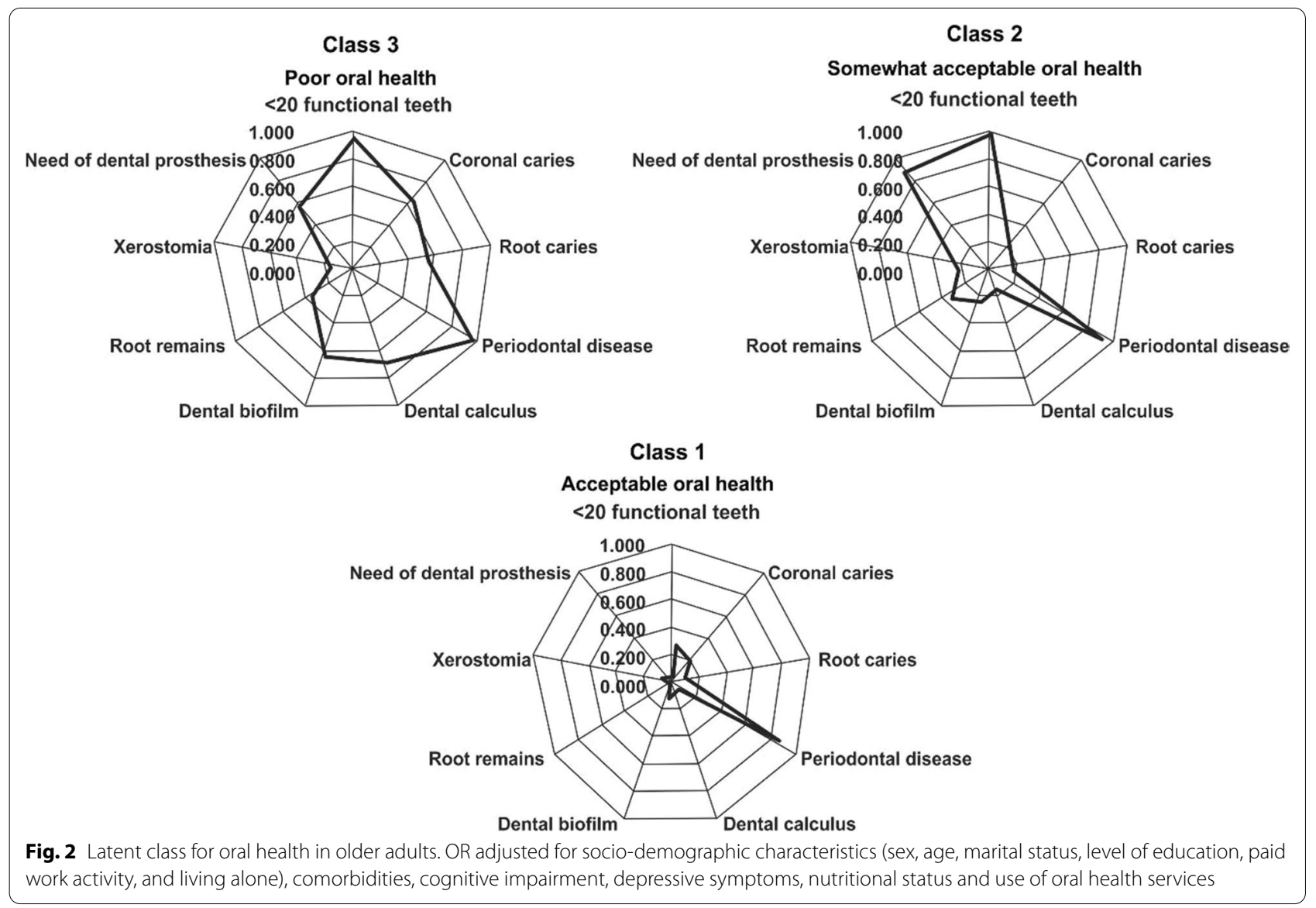


oral health. No association was noted for older adults with somewhat acceptable oral health compared to those with acceptable oral health (Fig. 3).

\section{Discussion}

For this study, we determined the strength of the association (OR) of the oral health categories at baseline $\left(t_{0}\right)$ and development of frailty over a 12-month period $\left(t_{1}\right)$ in older adults. The bivariate analysis found that the strength of the association is greater in edentulous older adults and those with poor oral health. After adjustment for the other variables under study, the association between edentulism, poor oral health, and developing frailty in that period remained.

In total, $18.0 \%(n=97)$ of the older adults included in this study developed frailty over a period of 12-months. This incidence rate was higher than those reported by Castrejón et al. and Ramsay et al. (14.8\% and 10.0\%, respectively) in older adults, in their respective threeyear follow-up studies. Likewise, the incidence rate in our study surpassed that found by Iwasaki et al. (14.9\%) in their five-year follow-up study in adults over age 75, as well as the overall incidence reported by Ofori-Asenso $(13.6 \%)$ in the meta-analysis of 46 studies with a median follow-up of three years in populations aged 60 years and over [14, 18, 34, 35].

Comparing this study with one conducted by Castrejón et al., there is a difference in the development of frailty of $3.2 \%$ ( $14.8 \%$ cumulative incidence of frailty). They also used frailty phenotype, but unlike this work, they evaluated unintentional weight loss of $5 \mathrm{~kg}$ in the last 6 months, the slowness of gait, and grip strength, which is evaluated subjectively. Therefore, there could have been a reporting bias and probably an underestimation of the results due to the subjectivity of the aforementioned frailty criteria. In addition, the population of this study are residents of a district that is part of a Mexico City government program, so it is possible that they are under constant review and receive some type of care [14].

The difference in the development of frailty in this study compared with Ramsay et al. is 8 points. Although they also used the frailty phenotype, this difference may be due to the fact that they evaluated grip strength subjectively and slow walking speed was determined by self-reporting of usual running rate. In addition, unintentional weight loss was ascertained by self-reporting of weight loss in the past 4 years. Therefore, there may have been an information bias and possible underestimation because of the subjectivity of the assessment regarding the above-mentioned frailty criteria $[18,36,37]$.

According to the LCA, a methodology to determine oral health typology, we considered three classes of oral health related to the studied parameters [6]. Doing so, we observed a stronger association between older adults with poor oral health and development of frailty over a 12-month period. Consequently, the LCA can be considered a useful tool for determining typology in other studies that need to classify older adults according to their oral health status [38].

Oral health ailments begin at early ages; without proper care, they can evolve into major problems at advanced ages. For example, tooth loss, edentulism, loss of clinical insertion, coronal and root caries, use of non-functional dental prosthesis (partial or total dentures), and chewing problems, among other conditions [9].

Oral health is generally evaluated in terms of deficits and indices, which does not provide a complete measure of oral health, like the patterns in this study [10]. Using latent class analysis for oral health conditions, we obtained a model of three classes in addition to the group of edentulous older adults. This is consistent with both Sánchez et al. and Ortiz et al., who also identified three classes in addition to edentulous participants, in a population covered by the social security system. It should be mentioned that, although the oral health deficits used

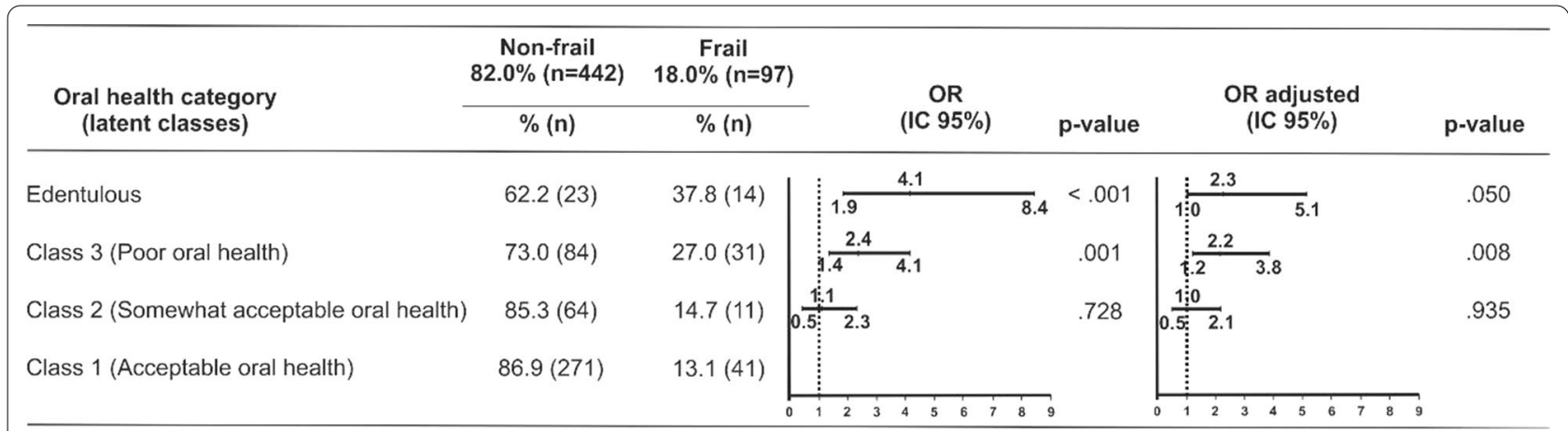

Fig. 3 Strength of the association (OR) between frailty and the oral health classes in older adults 
to perform the latent class analysis were not the same among the aforementioned studies, similarities were observed so far as the highest percentage of the population was classified with favorable oral health $[9,10]$.

Regarding edentulism and dental loss, several reports $[15,16,34]$ have identified tooth loss as a possible early indicator of frailty [39-41]. Dental loss, edentulism, and absent or inadequate dental prosthetic rehabilitations in older adults can affect several factors, such as nutrition [42-45], socialization, and quality of life [46, 47], which could probably lead to the development of frailty. Studies are needed to clarify the relationship between edentulism and tooth loss with the components of the frailty phenotype.

On the other hand, although a high probability of periodontal disease is observed among people with acceptable oral health, a high probability is not observed for other deficits. The probability of periodontal disease is higher among people who have more teeth; tooth loss cancels that probability. Also, edentulous people probably lost their teeth to periodontal disease, but this cannot be accurately determined. As for poor oral health condition, periodontal disease represents an important component.

Periodontal disease does not begin at an early age. It is an inflammatory process of periodontal tissues that is exacerbated when the disease is active. This can trigger higher levels of inflammatory markers, damage to tissue, or pathogenic bacteria can cause the gingival epithelium to initiate the inflammatory response in which epithelial cells release pro-inflammatory mediators such as macrophages, mast cells and polymorphonuclear cells, with secretion of interleukins IL-1 IL-6, IL-8 and tumor necrosis factor alpha (TNF- $\alpha$ ) and histamine, which amplify inflammation and could contribute to the development of frailty $[48,49]$.

Among the limitations of the study is the uneven distribution of participants in the different classes. It would thus be necessary to increase the size of the sample or implement other designs in which the number of participants in each group remains fixed. Another limitation is the loss to follow-up of some participants (18.7\%). The main reasons were not being located (48.4\%), followed by not agreeing to be interviewed or examined (31.5\%), which could have occurred because of illness or frailty. The literature has reported that the loss of participants during follow-up is associated with data missing not at random, so biased estimations may occur [50]. For these reasons, we suspect that the incidence of frailty could have been underestimated. Furthermore, being a community of older adults with social security coverage, the results cannot be generalized to the entire population of that age group.
An additional limitation was the evaluation of periodontal disease, which was defined as presence of clinical attachment loss $\geq 4 \mathrm{~mm}$ in at least one tooth. This measurement of periodontal disease generally considers people with at least moderate severity [51]. Therefore, a large number of individuals were classified as having the disease $(88.2 \%)$ without the possibility of identifying those with severe periodontal disease, who may have had the highest risk of frailty because of the constant inflammatory process $[5,8]$. Thus, the impact of each latent class could have modified the final result. It is necessary to continue studying the possible relationship between the inflammatory processes originated by periodontal disease and other diseases, in this case the development of frailty.

This study did not evaluate masticatory capacity with and without the use of prostheses. Therefore, other studies should consider it to determine if it has any implication in the development of frailty in older adults.

Hakeem et al. [16] and Tórres et al. [52] conducted literature reviews of studies with both cross-sectional and longitudinal designs, in which they report the association between clinically assessed oral health deficits and perception of oral health with frailty or any of its components in older adults. The number of teeth is among the main oral conditions associated with frailty, which is related to chewing problems and a need for rehabilitation with dental prostheses. This could limit food selection and processing, impacting nutritional status, which is one of the most recognized factors associated with the development of frailty. This could be a possible mechanism underlying the relationship between oral health and frailty [53]. There is a need for further research that explores the role of nutrition as a mediator between oral health and frailty.

With respect to the strengths of the study, one is its case-cohort design, in which cases develop according to the same chronological sequence of the case-control design nested in a cohort. The difference between these two designs is that controls in the case-cohort design are selected from the cohort with which the study began [20]. A longitudinal study can help establish a causal relationship between oral health and development of frailty over a short period of time. More years of follow-up would certainly show a greater incidence of frailty and the effect would remain significant in the fit analysis. Finally, using the frailty phenotype for the evaluation of the event of interest allows comparison with other studies. Yet, as far as we know, this is the first study to use a comprehensive approach to oral health and examine its relationship with the development of frailty.

Edentulism and poor oral health can be indicators of the presence or development of frailty, which in turn is 
considered as a potential public health problem in the older adult population [54,55], given its association with adverse health outcomes such as falls, impaired mobility, functional dependence, disability, hospitalization, and institutionalization [5, 21].

Further research will be needed to confirm the association between oral health and the development of frailty in older adults, using longitudinal studies with other populations, such as those who are institutionalized or do not have social security. In this way, the causal relationships of highly preventable diseases can be explored.

Lastly, changes in operational definitions of oral health deficits may probably modify the distribution of groups, so it would be advisable to hypothesize using different operational definitions or different cutoff points to evaluate behavior when predicting frailty.

\section{Conclusion}

The results of this study suggest that older adults with edentulous and poor oral health have an increased risk of developing frailty over a 12-month period. Given that oral health deficits can be prevented at all stages of life, intervention programs should be implemented to improve this population's oral health.

\begin{abstract}
Abbreviations
AIC: Akaike Information Criterion; BIC: Bayesian Information Criterion; CESD-R: Center for Epidemiologic Studies Depression Scale-Revised; COSFOMA: Cohort of Obesity, Sarcopenia, and Frailty of Older Mexican Adults; IMSS: Mexican Social Security Institute; LCA: Latent Class Analysis; LMR: Lo-Mendell-Rubin; MMSE: Mini-Mental State Examination; MNA: Mini Nutritional Assessment; OR: Odds Ratio; SD: Standard Deviation.
\end{abstract}

\section{Acknowledgements}

The authors wish to thank the older adults who participated in this study, as well as the authorities and staff from the Southern and Northern Delegations of the Mexican Institute of Social Security (IMSS) in Mexico City for supporting this study.

\section{Authors' contributions \\ LBV-O and SS-G were responsible for conceiving and designing the study. LBV-O and SS-G carried out the acquisition and analysis of the data. LBV-O, $S A B-Y, P A P, C G-P$ and $L M G-R$ were involved in the interpretation of the results. LBV-O, SAB-Y, PAP, CG-P, LMG-R and SS-G drafted the manuscript. LBV-O, SAB-Y, PAP, CG-P, LMG-R and SS-G revised and edited the manuscript. All authors contributed significantly, read and approved the final manuscript.}

\section{Funding}

The Cohort of Obesity, Sarcopenia, and Frailty of Older Mexican Adults (COSFOMA) was funded by grants from Health Research and Social Security Sector Fund SS/IMSS/ISSSTE/CONACYT (SALUD-2013-01-201112) and the Fund for the Promotion of Health Research (FIS/IMSS/PROT/PRIO/13/024), IMSS. The publication this paper was supported by a grant from the Secretaría de Educación, Ciencia, Tecnología e Innovación de la Ciudad de México CM-SECTEI/200/2020"Red Colaborativa de Investigación Traslacional para el Envejecimiento Saludable de la Ciudad de México (RECITES)".
Availability of data and materials

Data is available upon request. Contact e-mail: sergio.sanchezga@imss.gob. $\mathrm{mx}$.

\section{Declarations}

Ethics approval and consent to participate

All the stages of the research were carried out under the Declaration of Helsinki. All participants volunteered for the study, were informed of its scope, and provided written consent. This research protocol was approved by IMSS's National Committee for Scientific Research (Health Research Committee, Ethics Committee on Health Research, and Biosafety Committee on Health Research), registration number: R-2017-785-11). All participants signed an informed consent form before data gathering.

\section{Consent for publication}

Not applicable.

\section{Competing interests}

The authors declare that they have no competing interests.

\section{Author details}

${ }^{1}$ Facultad de Odontología, Universidad Nacional Autónoma de México, Ciudad de México, México. ${ }^{2}$ División de Estudios de Posgrado e Investigación, Facultad de Odontología, Universidad Nacional Autónoma de México, Ciudad de México, México. ${ }^{3}$ Facultad de Psicología, Universidad Nacional Autónoma de México, Ciudad de México, México. ${ }^{4}$ Instituto Nacional de Geriatría, Ciudad de México, México. ${ }^{5}$ Unidad de Investigación Epidemiológica y en Servicios de Salud, Área Envejecimiento, Centro Médico Nacional Siglo XXI, Instituto Mexicano del Seguro Social, Avenida Cuauhtémoc No. 330, Edificio CORCE, Tercer Piso. Col. Doctores. Alcaldía Cuauhtémoc, 06720 Ciudad de México, México.

Received: 7 February 2021 Accepted: 7 July 2021

Published online: 20 July 2021

\section{References}

1. Merchant RA, Morley JE, Izquierdo M. Exercise, aging and frailty: guidelines for increasing function. J Nutr Health Aging. 2021;25:405-9.

2. Organización Mundial de la Salud: Envejecimiento y ciclo de vida. https:// www.who.int/ageing/about/facts/es/ (2020). Accessed 17 Jan 2020.

3. Clegg A, Young J, lliffe S, Rikkert MO, Rockwood K. Frailty in elderly people. Lancet. 2013;381(9868):752-62.

4. Rockwood K. What would make a definition of frailty successful? Age Ageing. 2005;34(5):432-4.

5. Fried LP, Tangen CM, Walston J, Newman AB, Hirsch C, Gottdiener J, et al. Frailty in older adults: evidence for a phenotype. J Gerontol A Biol Sci Med Sci. 2001;56(3):M146-56.

6. Espinoza SE, Fried LP. Risk factors for frailty in the older adult. Clin Geriatr. 2007;15(6):37.

7. Hoogendijk EO, Afilalo J, Ensrud KE, Kowal P, Onder G, Fried LP. Frailty: implications for clinical practice and public health. Lancet. 2019;394:1365-75.

8. Petersen PE, Kandelman D, Arpin S, Ogawa H. Global oral health of older people-call for public health action. Community Dent Health. 2010;27(4 Suppl 2):257-67.

9. Ortíz-Barrios LB, Granados-García V, Cruz-Hervert P, Moreno-Tamayo K, Heredia-Ponce E, Sánchez-García S. The impact of poor oral health on the oral health-related quality of life (OHRQoL) in older adults: the oral health status through a latent class analysis. BMC Oral Health. 2019;19(1):141.

10. Sánchez-García S, Heredia-Ponce E, Cruz-Hervert P, Juárez-Cedillo T, Cárdenas-Bahena A, García-Peña C. Oral health status in older adults with social security in Mexico City: latent class analysis. J Clin Exp Dent. 2014;6(1):e29-35.

11. Castrejón-Pérez RC, Borges-Yáñez SA. Frailty from an oral health point of view. J Frailty Aging. 2014;3(3):180-6. 
12. Castrejón-Pérez RC, Borges-Yáñez SA, Gutiérrez-Robledo LM, Ávila-Funes JA. Oral health conditions and frailty in Mexican community-dwelling elderly: a cross sectional analysis. BMC Public Health. 2012;12:773.

13. Kamdem B, Seematter-Bagnoud L, Botrugno F, Santos-Eggimann B. Relationship between oral health and Fried's frailty criteria in communitydwelling older persons. BMC Geriatr. 2017;17:174

14. Castrejón-Pérez RC, Jiménez-Corona A, Bernabé E, Villa-Romero AR, Arrive $E$, Dartigues JF, et al. Oral disease and 3-year incidence of frailty in Mexican older adults. J Gerontol A Biol Sci Med Sci. 2017:72:951-7.

15. Watanabe $Y$, Hirano H, Arai H, Morishita S, Ohara Y, Edahiro A, et al. Relationship between frailty and oral function in community-dwelling elderly adults. J Am Geriatr Soc. 2017:65:66-76.

16. de Andrade FB, Lebrao ML, Santos JL, Duarte YA. Relationship between oral health and frailty in community-dwelling elderly individuals in Brazil. J Am Geriatr Soc. 2013;61:809-14.

17. Hakeem FF, Bernabé E, Sabbah W. Association between oral health and frailty: a systematic review of longitudinal studies. Gerodontology. 2019:36(3):1-11.

18. Ramsay SE, Papachristou E, Watt RG, Tsakos G, Lennon LT, Papacosta AO, Moynihan P, Sayer AA, Whincup PH, Wannamethee SG. Influence of poor oral health on physical frailty: a population-based cohort study of older British men. J Am Geriatr Soc. 2018;66(3):473-9.

19. Tanaka T, Takahashi K, Hirano H, Kikutani T, Watanabe Y, Ohara Y, et al. Oral frailty as a risk factor for physical frailty and mortality in communitydwelling elderly. J Gerontol Ser A. 2018;73(12):1661-7.

20. Gordis L. Epidemiología. 5th ed. España: Elsevier; 2014.

21. Sánchez-García S, García-Peña C, Salvà A, Sánchez-Arenas R, GranadosGarcía V, Cuadros-Moreno J, et al. Frailty in community-dwelling older adults: association with adverse outcomes. Clin Interv Aging. 2017;12:1003-11

22. Gutiérrez JP, Rivera-Dommarco J, Shamah-Levy T, Villalpando-Hernández S, Franco A, Cuevas-Nasu L, Romero-Martínez M, Hernández-Ávila M. Encuesta Nacional de Salud y Nutrición 2012. Resultados Nacionales. Cuernavaca: Instituto Nacional de Salud Pública; 2012. https://ensanut. insp.mx/encuestas/ensanut2012/doctos/informes/ENSANUT2012Resu ItadosNacionales.pdf. Accessed 16 Jan 20.

23. Petersen PE, Baez RJ, World Health Organization. Oral health surveys: basic methods. 5th ed. World Health Organization; 2013.

24. Thomson WM, Chalmers JM, Spencer AJ, Williams SM. The Xerostomia Inventory: a multi-item approach to measuring dry mouth. Community Dent Health. 1999;16(1):12-7.

25. Ettinger RL, Jakobsen JR. A comparison of patient satisfaction and dentist evaluation of overdenture therapy. Community Dent Oral Epidemiol. 1997;25(3):223-7.

26. Elixhauser A, Steiner C, Harris DR, Coffey RM. Comorbidity measures for use with administrative data. Med Care. 1998:36(1):8-27.

27. de Beaman SR, Beaman PE, García-Peña C, Villa MA, Heres J, Córdova A, et al. Validation of a modified version of the mini-mental state examination (MMSE) in Spanish. Aging Neuropsychol Cogn. 2004;11(1):1-11.

28. Sánchez-García S, Juárez-Cedillo T, Gallegos-Carrillo K, Gallo JJ, Wagner FA, García-Peña C. Frecuencia de los síntomas depresivos entre adultos mayores de la Ciudad de México. Salud Ment. 2012;35(1):71-7.

29. Guigoz Y. The Mini Nutritional Assessment (MNA) review of the literatureWhat does it tell us? J Nutr Health Aging. 2006;10(6):466-87.

30. Kendzor DE, Caughy MO, Owen MT. Family income trajectory during childhood is associated with adiposity in adolescence: a latent class growth analysis. BMC Public Health. 2012;12:611.

31. Jung T, Wickrama KAS. An introduction to latent class growth analysis and growth mixture modeling. Soc Personal Psychol Compass. 2008;2:302-17.

32. Akaike H. Factor analysis and the AIC. Psychometrika. 1987;52:317-32.

33. Schwartz G. Estimating the dimension of a model. Ann Stat. 1978;6:461-4.

34. Iwasaki M, Yoshihara A, Sato M, Minagawa K, Shimada M, Nishimuta M, Ansai T, Yoshitake Y, Miyazaki H. Dentition status and frailty in communitydwelling older adults: a 5-year prospective cohort study. Geriatr Gerontol Int. 2018;18(2):256-62.

35. Ofori-Asenso R, Chin KL, Mazidi M, Zomer E, llomaki J, Zullo AR, Gasevic D, Ademi Z, Korhonen MJ, LoGiudice D, Bell JS, Liew D. Global incidence of frailty and prefrailty among community-dwelling older adults: a systematic review and meta-analysis. JAMA Netw Open. 2019;2(8):e198398.

36. Sackett DL. Bias in analytic research. J Chron Dis. 1979:32:51-63.

37. Wynder EL. Investigator bias and interviewer bias: the problem of systematic error in epidemiology. J Clin Epidemiol. 1994;47:825-7.

38. Heredia-Ponce E, Irigoyen-Camacho AE, Sánchez-García S. Oral health status of institutionalized older women from different socioeconomic positions. J Health Care Poor Underserved. 2017;28(4):1462-76.

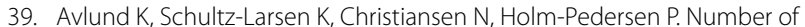
teeth and fatigue in older adults. J Am Geriatr Soc. 2011;59(8):1459-64.

40. Hämäläinen P, Rantanen T, Keskinen M, Meurman JH. Oral health status and change in handgrip strength over a 5-year period in 80-year-old people. Gerodontology. 2004;21(3):155-60.

41. Takata Y, Ansai T, Awano S, Hamasaki T, Yoshitake Y, Kimura Y, Sonoki K, Wakisaka M, Fukuhara M, Takehara T. Relationship of physical fitness to chewing in an 80-year-old population. Oral Dis. 2004;10(1):44-9.

42. Ritchie CS, Joshipura K, Silliman RA, Miller B, Douglas CW. Oral health problems and significant weight loss among community-dwelling older adults. J Gerontol A Biol Sci Med Sci. 2000;55(7):M366-71.

43. Rodrigues HL, Scelza MFZ, Boaventura GT, Custódio SM, Moreira EAM, Oliveira D de L. Relation between oral health and nutritional condition in the elderly. J Appl Oral Sci Rev FOB 2012;20(1):38-44.

44. Marcenes W, Steele JG, Sheiham A, Walls AWG. The relationship between dental status, food selection, nutrient intake, nutritional status, and body mass index in older people. Cad Saude Publica. 2003;19(3):809-16.

45. Sheiham A, Steele JG, Marcenes W, Finch S, Walls AWG. The relationship between oral health status and Body Mass Index among older people: a national survey of older people in Great Britain. Br Dent J. 2002;192(12):703-6.

46. Castrejón-Pérez RC, Borges-Yáñez SA, Irigoyen-Camacho ME. Validación de un instrumento para medir el efecto de la salud bucal en la calidad de vida de adultos mayores mexicanos. Rev Panam Salud Publica. 2010;27(5):321-9.

47. Sánchez-García S, Juárez-Cedillo T, Reyes-Morales, de la Fuente-Hernández J, Solórzano-Santos F, García-Peña C. Estado de la dentición y sus efectos en la capacidad de los ancianos para desempeñar sus actividades habituales. Salud Publica Mex. 2007:49:173-81

48. Solís-Suárez DL, Pérez-Martínez IO, García-Hernández AL. Mecanismos inflamatorios en la destrucción periodontal. Rev Odont Mex. 2019;23(3):159-72.

49. Gu Y, Wu W, Bai J, Chen X, Chen X, Yu L, et al. Association between the number of teeth and frailty among Chinese older adults: a nationwide crosssectional study. BMJ Open. 2019;9:e029929.

50. Kristman V, Manno M, Côté P. Loss to follow-up in cohort studies: how much is too much? Eur J Epidemiol. 2004;19:751-60.

51. Eke PI, Page RC, Wei L, Thornton-Evans G, Genco RJ. Update of the case definitions for population-based surveillance of periodontitis. J Periodontol. 2012;83(12):1449-54.

52. Torres LH, Tellez M, Hilgert JB, Hugo FN, de Sousa MD, Ismail Al. Frailty, Frailty Components, and Oral Health: A Systematic Review. J Am Geriatr Soc. 2015;63:2555-62.

53. Castrejón-Pérez RC. Exploring associations between oral health and frailty in community-dwelling older people. J Frailty Aging. 2021; 10:56-62.

54. Collard RM, Boter $\mathrm{H}$, Schoevers RA, Oude Voshaar RC. Prevalence of frailty in community-dwelling older persons: a systematic review. J Am Geriatr Soc. 2012;60(8):1487-92.

55. Cesari M, Prince M, Thiyagarajan JA, De Carvalho IA, Bernabei R, Chan $P$, Gutierrez-Robledo LM, Michel JP, Morley JE, Ong P, Rodriguez Manas L, Sinclair A, Won CW, Beard J, Vellas B. Frailty: an emerging public health priority. J Am Med Dir Assoc. 2016;17(3):188-92.

\section{Publisher's Note}

Springer Nature remains neutral with regard to jurisdictional claims in published maps and institutional affiliations. 